\title{
Sub specie saeculi, sub specie aeterni: tempo e eternidade no jovem Nietzsche
}

Sub specie saeculi, sub specie aeterni: Time and Eternity in Young Nietzsche

Eduardo Nasser Universidade Federal do $A B C$

\section{RESUMO}

Para o jovem Nietzsche, a modernidade marca o início do ocaso da cultura ocidental em virtude da glorificação do conhecimento. Esse aspecto é a causa para que o homem moderno fique enclausurado numa perspectiva realista, sendo incapaz de se libertar do constrangimento infligido pelo vir-a-ser. Para reverter a condenação imposta à cultura pelo socratismo, é preciso restituir os direitos da arte, pois somente a arte viabiliza a recuperação do laço com a eternidade, fornecendo meios para o homem se proteger dos efeitos do tempo. Isso ocorre especialmente no âmbito da arte musical, quer em sua vertente apolínea (ritmo), quer em sua vertente dionisíaca (harmonia), na medida em que a supremacia das aparências ante a arte é enfraquecida.

\section{PALAVRAS-CHAVE}

Tempo; Eternidade; Linguagem; Arte; Mito.

\begin{abstract}
For the Young Nietzsche, modernity sets the beginning of the decline of western culture, by virtue of the glorification of knowledge. This aspect causes the seclusion of modern man in a realistic perspective, unable to free himself from the constraint inflicted by the becoming. To revert this condemnation imposed on culture by Socratism, it is necessary to restitute Art's rights, since only art enables the recovery of the bond with eternity, giving men the means to protect himself from the effects of time. This happens especially in the music realm, either in its Apollonian aspect (rhythm) or in its Dyonisian (harmonic) one, in that the supremacy of appearances before art is weakened.
\end{abstract}

\section{KEY WORDS}

Time; Eternity; Language;

Art; Myth. 


\section{Introdução}

O vir-a-ser é a fonte da fastidiosa agonia da modernidade que impede a elevação da cultura. Essa é a posição de Nietzsche antes da mudança de temperamento ocorrida em meados da década de 1870 , e revelada em Humano, demasiado Humano, que tem na filosofia histórica o alicerce intelectual de uma cultura próspera. ${ }^{I}$ Com efeito, como bem mostrou Otto Most em Zeitliches und Ewiges in der Philosophie Nietzsches und Schopenhauers, desde os seus exercícios literários e filosóficos mais primevos, Nietzsche identificou no vir-a-ser um objeto de inquietude que contrastava com o seu deslumbramento com a ideia de eternidade. Most trata de um Nietzsche ainda adolescente — final de I850 e início de I860 —, cujos escritos oferecem uma ênfase surpreendente ao vir-a-ser, especialmente em suas observaçōes intrigadas de fenômenos naturais, como ventos e tempestades. Todavia, esse aparente fascínio encoberta uma visão desconsolada, porquanto o reconhecimento do vir-a-ser na natureza é acompanhado pela admissão de que tudo caminha para o perecimento. É, então, na expectativa de sobrepujar o sofrimento gerado que é despertada a atração pela eternidade. "Pela realização da existência humana e sua transitoriedade [Vergänglichkeit], Nietzsche incorpora subsequentemente o conceito de eternidade" ${ }^{2}$ Esse amparo será encontrado no conceito cristão de eternidade, cujo significado dilui as ideias de incompletude, sucessão e mudança, congruente, enfim, com a pretensão de enfrentamento do vir-a-ser. ${ }^{3}$

Esse esquema poderia ter um alcance restrito se se aceita a tese bastante disseminada de que Nietsche rompe com o cristianismo por volta de 1865, após sua inserção social num meio esclarecido que promove um tratamento dessacralizado das escrituras através do método histórico-crítico. Most dá assentimento a essa tese sem, contudo, entender que, com isso, Nietzsche renuncie ao seu compromisso de restituir os direitos da eternidade; suas primeiras obras, O Nascimento da Tragédia e as Considerações Extemporâneas, ainda são conduzidas por esse propósito. ${ }^{4}$ Eu já busquei demonstrar que Nietzsche não rompe realmente com o cristianismo na década de 1860; ele usa o método histórico-crítico como um instrumento que fortalece a incorporação da prática da religiosidade emancipada da bíblia e das autoridades, em alguma medida aproximando-se do deísmo de Voltaire e Lessing. 'Todavia, a asserção de Most é, no essencial, admissível, conquanto ele não tenha realmente explicitado de que modo se dá a defesa da eternidade

Cf. Nasser, 2015, pp. 88-90.

2 Most, 1977, p. I05.

3 Cf. Ibid., pp. II3-II5.

4 Cf. Ibid., p. I25.

5 Cf. Nasser, 20I4, pp. I47-I64. 
nos primeiros livros publicados por Nietzsche. Nesse artigo eu procurarei levar esse empreendimento adiante. Ocupar-me-ei da obra $O$ Nascimento da Tragédia, bem como das conferências, cursos e anotações do período. ${ }^{6}$ A hipótese que eu apresento é que Nietzsche encontra no âmbito da arte um novo caminho para a eternidade. Importante destacar que continua sendo um empreendimento de cunho religioso, embora situado num contexto pagão. "O período da arte é uma continuação do período que forma o mito e a religião. Arte e religião fluem de uma mesma fonte". Trata-se, num certo sentido, do resgate de uma religiosidade mais genuína, projeto já bastante influente na Alemanha desde Herder e os românticos, que almeja resistir à racionalização e moralização da religião imposta por segmentos protestantes, como também ao excessivo realismo contido na bíblia, que inviabiliza a irrupção de uma cultura mítica. ${ }^{8}$ Considerando-se que, ao contrário das religiôes mais imaginativas dos antigos, as religiōes na modernidade "degeneram, em seus fundamentos, em religiōes doutas [Gelehrtenreligionen]", elas se mantêm imersas no mundo dos conceitos, não oferecendo verdadeiramente um meio de desligamento do realismo e, no limite, do vir-a-ser.

\section{Sub specie saeculi}

Para o jovem Nietzsche, a modernidade marca o início do ocaso da cultura ocidental em virtude da glorificação do conhecimento. Esse aspecto é a causa para que o homem moderno fique enclausurado numa perspectiva realista, sendo incapaz de se libertar do constrangimento infligido pelo vir-a-ser.

As raízes da modernidade estão no socratismo, que exprime uma irrefreável propensão à cientificidade, abreviando o fim da cultura artística da época trágica dos gregos. "Com Sócrates penetra o princípio da ciência". A ciência opera unicamente com palavras, requisitando demonstraçôes argumentadas e dialogadas. Consiste na realização do impulso apolíneo; mas também no seu desvio. Da "mais elevada preparação apolínea" a "ciência é uma consequência"; "o diálogo é o lugar privilegiado do apolíneo". ${ }^{\text {.2 }}$ Todavia, com o advento do

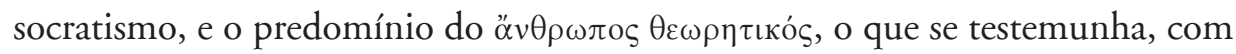

6 Eu já abordei esse assunto no contexto da II Consideração Extemporânea. Cf. Nasser, 20I7, pp. 57-95.

7 Fragmento Póstumo 9 [94] de I87I, KSA 7.309.

8 Cf. Williamson, 2017, pp. 33-35, 65 e 66.

9 O Nascimento da Tragédia \$ I8, KSA I.II7.

Io Fragmento Póstumo I [27] do outono de I869, KSA 7.I7.

II Fragmento Póstumo 7 [62] do final de I870/abril de I871, KSA 7.I52.

I2 Fragmento Póstumo 7 [94] do final de I870/abril de I87I, KSA 7.I59. 
efeito, é uma "sobrecarga do impulso apolíneo". ${ }^{13} \mathrm{E}$ isso ocorre quando se passa a valorizar unicamente elementos não estéticos produzidos por esse impulso. "A ciência enquanto impulso apolíneo (enquanto apolíneo em antagonismo à arte)". ${ }^{14}$ A ciência se apropria do apolíneo, subtraindo a apreciação das belas formas e o entrelaçamento entre apolíneo com dionisíaco, unidade constitutiva da arte trágica. Esse acontecimento institui uma cultura fortemente teórica, centrada nas palavras, e artisticamente debilitada, especialmente para a sensibilidade musical. No campo estético, faz-se notar esse efeito no crescimento da cultura operística, que trata a música como "serva" e a "palavra do texto como senhor", dirigida a ouvintes "amusicais". ${ }^{\text {Is }}$ O prejuízo gerado por esse quadro, então reinante, é que ele inevitavelmente redunda no enfraquecimento da cultura, posto que as "palavras são os signos mais deficientes".

Para o jovem Nietzsche, as palavras manifestam somente uma parte residual de uma dimensão mais vasta da linguagem. A palavra é a "superfície de um mar agitado, onde a tempestade reina nas profundezas". ${ }^{17}$ A linguagem possui diferentes estratos, inconscientes, que variam conforme sua maior acuidade simbólica. Símbolo significa aqui a "transposição [Übertragung] de uma coisa para uma esfera completamente distinta". ${ }^{18}$ Nesse sentido, a linguagem musical é a linguagem primordial; "a música é a verdadeira [eigentlich] linguagem do universal”. I9 Isso acontece porque através da música obtemos uma simbólica da vontade..$^{20} \mathrm{~A}$ música é uma linguagem com valor metafísico, não estando referida ao particular, inserido na realidade dos fenômenos; o som "não pertence ao mundo dos fenômenos, mas fala do que nunca aparece [Nieerscheinenden]". ${ }^{21}$ De acordo com o entendimento que Nietzsche possui de símbolo, a música não deixa de possuir um caráter particular, não sendo realmente análoga à vontade — o que afasta Nietzsche da acepção aparentemente semelhante que nomes como Moritz e Schelling possuem do símbolo e sua relação com a obra de arte. Porém, em virtude de seu objeto, trata-se de uma linguagem notadamente mais geral — "o

\footnotetext{
I3 Fragmento Póstumo 7 [64] do final de I870/abril de I87I, KSA 7.I53.

I4 Fragmento Póstumo 7 [IoI] do final de I870/abril de I87I, KSA 7.I6I.

I5 O Nascimento da Tragédia $\$$ I9, KSA I.I26.

I6 Fragmento Póstumo 2 [II] do inverno de I869-70/primavera de I870, KSA 7.48.

17 Fragmento Póstumo 2 [Io] do inverno de I869-70/primavera de I870, KSA 7.48.

I8 Fragmento Póstumo 3 [20] do inverno de I869-70/primavera de I870, KSA 7.66.

I9 Fragmento Póstumo 9 [88] de I87I, KSA 7.306.

20 Cf. $A$ Visão dionisíaca de Mundo $\$$ 4, KSA I.574. O Nascimento da Tragédia $\$$ 19, KSA I.IO7.

2I Fragmento Póstumo I6 [13] do verão de I871/primavera de I872, KSA 7.397.
} 
mundo do som [...] deve estar mais relacionado à vontade"22 —, ao contrário do outro estrato linguístico identificado por Nietzsche: a linguagem dos gestos. A linguagem dos gestos corresponde ao lado intuitivo da linguagem; consiste na linguagem gestual que simboliza as representaçôes de acompanhamento. É uma imagem duplicada: o gesto é uma imagem que alude a uma outra imagem, as representaçōes de acompanhamento dos sentimentos. ${ }^{23}$ Há uma ruptura, assim, com a linguagem musical, não intuitiva e alheia ao fenomenal. Porém, é preciso compreender que a imagem é "metáfora [Gleichniss] da natureza dionisíaca do som". ${ }^{24}$ Isso significa que não há uma ruptura total entre som e imagem, pois a produção das imagens não deve ser entendida como imitação da natureza. A imagem é uma produção necessária da música, já que a imagem cumpre um papel crucial no drama metafísico de Nietzsche, exercendo efeito curativo para o sofrimento inerente ao mundo.

A linguagem, em sua origem, está assentada numa esfera artística. "Os sinais artísticos na gênese da linguagem: imagem e som". ${ }^{25}$ Sem embargo, com a irrupção das palavras e conceitos, esse fundamento estético da linguagem é perdido. A palavra é formada pelo som e pela simbolização gestual da imagem realizada pela boca. A linguagem proposicional consiste, portanto, na unificação dos dois grandes estratos inconscientes da linguagem. Um tipo de desvio, contudo, ocorre quando a palavra conquista estatuto de conceito. Nietzsche dirá que o conceito surge mediante a intervenção da memória, que impõe regularidade à palavra. Mas, com isso, o "som esvaece", e o conceito se torna "somente o símbolo da representação de acompanhamento". ${ }^{26}$ Importante destacar que Nietzsche entende o conceito como um tipo de imagem; o conceito é "na origem uma imagem". ${ }^{27}$ Dessa forma, o conceito, enquanto símbolo da representação de acompanhamento, é a imagem de uma imagem, assim como o gesto. ${ }^{28}$ Entretanto, se a imagem está primordialmente conectada ao som, conexão enfraquecida quando da passagem

22 Fragmento Póstumo 3 [37] do inverno de I869-70/primavera de I870, KSA 7.70.

23 Cf. A Visão dionisíaca de Mundo $\$ 4$, KSA I.572 e 573.

24 Fragmento Póstumo 8 [29] do inverno de I870-7I/outono de I872, KSA 7.232.

25 Fragmento Póstumo 8 [72] do inverno de I870-71/outono de I872, KSA 7.249.

26 A Visão dionisíaca de Mundo $\$ 4$, KSA I. 576.

27 Fragmento Póstumo 8 [4I] do inverno de I870-7I/outono de I872, KSA 7.238.

28 Esse esquema, que coloca o conceito como o último elo de transposiçôes linguísticas, derivado de um patamar estético que encerra o pensamento - contrariando, portanto, as teorias iluministas da linguagem — , pauta as conhecidas reflexões sobre linguagem que aparecem no caderno PIzo e Sobre Verdade e Mentira no Sentido extra-moral. Existem, porém, diferenças significativas que concernem, acima de tudo, as posiçôes acerca da metafísica, bem como as tensões existentes entre uma concepção musical e outra retórica da linguagem, como já mostrou Behler. Cf. Behler, 1994, pp. 99-III. 
para a palavra e conceito, então o conceito perde o laço metafísico ensejado pela simbólica da música. Um conceito jamais poderia almejar simbolizar a vontade, pois isso demandaria engendrar o som a partir de conceitos, algo que, como nos diz Nietzsche, é "bizarramente equivocado". ${ }^{29}$ Resta à linguagem proposicional, hegemônica no domínio da consciência, unicamente a referência a representações. "Mas o que simboliza a palavra? Sem dúvida somente representaçóes". ${ }^{\circ}$

Essas apreciações de Nietzsche sobre a linguagem colocam em evidência que uma cultura governada por palavras e conceitos, como a cultura teórica criada com o socratismo, só pode possuir em seu horizonte o mundo das aparências, confusamente sentido como única realidade. Um evento que retrata com clareza o abandono da ligação com a metafísica na cultura, antepondo as aparências, pode ser identificado nas tragédias de Eurípedes, que, representativas do socratismo estético, afeitas à "frieza do pensamento" ao invés da "calma apolínea" os diálogos das personagens, a ação, findando numa "via naturalista e inartística" ${ }^{2}$ Testemunha-se aqui o nascimento da arte enquanto imitação da natureza. $\mathrm{Na}$ estética musical essa conversão antimetafísica da arte se faz notar quando a música passa a ser guiada pelo propósito mais prosaico de refletir as aparências, sendo uma fonte de distração, como a música que imita batalhas, desobrigada da tarefa mais elevada de ser um "espelho da vontade do mundo". Eurípedes encarnou de forma pioneira o orgulho do homem moderno em ter como seu horizonte definitivo o "natural e real [Wirklichen]", o "polo oposto de todo idealismo". ${ }^{34}$ Todavia, esse orgulho realista, preponderante na modernidade, esconde um efeito profundamente danoso. Pois, restringindo-se ao mundo das aparências, o homem passa a ser uma vítima indefesa das implacáveis investidas do tempo.

O realismo da vida atual, as ciências da natureza, possuem uma inacreditável força de estremecimento da cultura [bildungsstürmerische]; deve-se a ela opor a arte. A cultura clássica está sempre ameaçada de degenerar em tímida erudição. Falta a devoção religiosa [Frömmigkeit] da arte: atroz manifestaçáo de Kronos, o tempo que devora os seus próprios filhos. ${ }^{35}$

O mundo das aparências é o mundo empírico revestido pelo vir-a-ser. A

29 Fragmento Póstumo I2 [I] da primavera de I87I, KSA 7.363.

30 Fragmento Póstumo I2 [I] da primavera de I87I, KSA 7.360.

3I Fragmento Póstumo I4 [9] da primavera de I87I/início de I872, KSA 7.377.

32 O Nascimento da Tragédia $\$$ I2, KSA I.85.

33 O Nascimento da Tragédia $\$$ I7, KSA I.II2.

34 O Nascimento da Tragédia $\$ 7$, KSA I.55.

35 Fragmento Póstumo 5 [28] de setembro de I870/janeiro de I87I, KSA 7.99. 
aparência é o "verdadeiramente não-ser", o "ininterrupto vir-a-ser no tempo, espaço e causalidade", ou, em outras palavras, "o mundo empírico" "36; "neste mundo do não-ser [Nicht-Seienden], da aparência [Schein], tudo deve estar em vira-ser" ${ }^{37} \mathrm{O}$ vir-a-ser é um fim em si mesmo. E isso acontece em virtude da natureza peculiar do tempo. Stambaugh soube identificar que, nessa época, Nietzsche possui uma visão do tempo como algo contraditório; tempo consiste em instantes que destroem uns aos outros. ${ }^{38}$ Seria preciso acrescentar que essa visão é uma herança direta de Schopenhauer, que compreende o tempo como essencialmente sucessivo, desprovido de passado e futuro, limitando-se a um amontoado de instantes fugazes que se consomem; donde Kronos representar a natureza do tempo. "Cada instante da duração", diz Schopenhauer, "só existe com a condição de destruir o precedente que o engendrou, para ser também, em breve, por sua vez anulado; o passado e o futuro, abstração feita das consequências possíveis que eles contêm, são coisas tão vãs como o mais vão dos sonhos, e o mesmo pode-se dizer do presente, limite sem extensão e sem duração entre os dois". ${ }^{39}$

Sem ter realmente passado ou futuro, resta ao homem moderno idolatrar o fugidio instante atual; ele é movido por uma "leviana adulação do presente", encarando tudo "sub specie saeculi, o tempo do agora [Jetztzeit]". ${ }^{40}$ Nietzsche novamente se apropria de Schopenhauer. Em Parerga e Paralipomena, Schopenhauer emprega o conceito de Jetztzeit contra hegelianos, como também contra os representantes do movimento Jungen Deutschland, liderado por Ludolf Wienbarg ${ }^{4 \mathrm{I}}$, devido à arrogância e inocência de acreditar que o agora atual tem mais valor que os agoras anteriores, prenunciadores de sua chegada, e também devido à ignorância em reconhecer o caráter irremediavelmente volátil do presente, fonte de ansiedade em que "nenhum homem ainda se sentiu inteiramente feliz". ${ }^{42}$

36 O Nascimento da Tragédia $\$$ 4, KSA I.38 e 39.

37 Fragmento Póstumo Io [I] do início de I871, KSA 7.334.

38 Stambaugh também traça uma separação entre as visões de tempo da juventude e maturidade de Nietzsche, mesmo que por vezes essa separação não seja verdadeiramente rigorosa. Haveria duas concepçôes de tempo: uma em que o tempo é retratado como instantes que se consomem insaciavelmente e outra em que o tempo é cíclico. Cf. Stambaugh, I959, p. I e 2.

39 Schopenhauer, 1986, p. 36. Essa descrição fortemente cratiliana do tempo será parafraseada por Nietzsche em A Filosofia na Época Trágica dos Gregos, no capítulo v dedicado a Heráclito, o que confirma a concordância com Schopenhauer acerca da natureza do tempo. Cf. A Filosofia na Época Trágica dos Gregos, KSA I.823 e 824. Eu já fiz alusão a esse episódio. Cf. Nasser, 2015, p. 92 e 93.

40 O Nascimento da Tragédia $\$ 23$, KSA I.I49.

4I Cf. Schmidt, 20I2, p. 399.

42 Schopenhauer, 1986, p. 339. 
O endeusamento do presente parece ser o sintoma de um homem tomado pelo desalento, que, iludindo-se, tenta se apegar ao último rastro de plenitude do ser, sem nunca de fato lograr êxito, já que o instante está permeado de não-ser.

\section{Sub specie aeterni}

Para reverter a condenação imposta à cultura pelo socratismo, é preciso restabelecer os direitos da arte, pois somente a arte fornece meios para o homem se proteger dos efeitos do tempo ${ }^{43}$. Isso ocorre especialmente no âmbito da arte musical, quer em sua vertente apolínea (ritmo), quer em sua vertente dionisíaca (harmonia), na medida em que a supremacia das aparências ante a arte é enfraquecida.

\section{a) Ritmo}

Nietzsche manifesta interesse pelo tema do ritmo desde 1864, tendo ministrado cursos quando na Basileia entre 1869 e I874, período em que elabora a sua tese heterodoxa, contra as influentes posições de Westphal, de que existe uma incompatibilidade entre as concepçóes antiga e moderna de ritmo. ${ }^{44}$ Ele almeja com isso desvendar o caráter puramente temporal do ritmo nos gregos, incompatível com a teoria do ictus, pregada pelos ritmistas modernos, intimamente associada com a linguagem falada, que basicamente entende o ritmo por meio de diferenças nos acentos das sílabas. "Não se encontra ictus nos antigos". ${ }^{45}$ Nietzsche retira o suporte teórico para essa tese de Aristoxeno, cuja abordagem aristotélica do ritmo aparta o domínio do ritmo em si (forma) e o domínio que acolhe o ritmo (matéria). ${ }^{46} \mathrm{O}$ ritmo não é perceptível sem a relação com os objetos; mas ele não é redutível ao objeto mesmo. Esse domínio próprio ao ritmo é o tempo. "O ritmo [Takt] não possui modelo na natureza", sendo "a sensação mais originária do tempo, a forma do tempo mesmo". ${ }^{47}$ Essa tese, notadamente inovadora, ultrapassa uma mera disputa filológica, servindo de veículo para Nietzsche incrementar o seu projeto de reforma estética antimoderna, visto que temos nos gregos os instrumentos para a arte se distanciar de sua servidão ao mundo das aparências. Por essa razão que Nietzsche afirma que a música grega, livre da entonação de palavras, da acentuação musical, redutível ao "ritmo temporal" ao invés do "ritmo de intensidades", é a "mais ideal". ${ }^{8}$

43 Destaque-se que essa estratégia estética de confrontação concorre com outra, epistemológica, que aponta para o caráter ideal do tempo. Cf. Nasser, 2015, pp. 30-43.

44 Cf. Carta a Friedrich Ritschl de 30 de dezembro de I870, кsв 3.I73.

45 Zur Theorie der quantitirenden Rhythmik, KGW II, 3.274.

46 Sobre a importância de Aristoxeno no contexto dos estudos rítmicos de Nietzsche, cf. Porter, 2000, pp. I38-I43.

47 Fragmento Póstumo 9 [II6] de I871, Ksa 7.317 e 318.

48 Fragmento Póstumo 9 [III] de I871, KSA 7.316. 
Aqui é preciso ter alguma cautela. Pois quando Nietzsche diz que o ritmo é a forma do tempo, trata-se de um tempo já moldado pela forma, distinto do tempo fugaz do mundo empírico. Retomando uma ideia de Aristoxeno, Nietzsche dirá que "ritmo é a ordenação do tempo". ${ }^{49} \mathrm{O}$ ritmo se sobrepõe ao vir-a-ser "para que o ritmo possa ser, é preciso que exista multiplicidade e vir-a-ser [...] o ritmo é a forma do vir-a-ser, em geral a forma do mundo dos fenômenos" ${ }^{5 \circ}$ Essa formalização acontece mediante uma espacialização do tempo. O menor ritmo, ou o menor tempo, o chronos prôtos, imprime paradas no fluxo, inibindo o caráter destrutivo do tempo do mundo empírico. ${ }^{\text {sI }} \mathrm{O}$ tempo investido de ritmo gera proporçôes de longo e curto que faz com que apreciemos "a arquitetônica espacial, não o temporal". ${ }^{2}$ Consiste no resultado peculiar às artes plásticas de "petrificação do momento". ${ }^{3}$ A arquitetônica do ritmo, que sujeita a mudança, condiz com o impulso apolíneo na arte. A música enquanto apolínea é "somente o ritmo", uma "arquitetura de sons". ${ }^{44}$ Há um interesse intuitivo que move a composição do ritmo e o ordenamento do tempo. ${ }^{55}$ É precisamente esse efeito visual suscitado que Nietzsche realça no ritmo dos antigos, para quem o "ritmo escutado era somente visivel, não audível". ${ }^{6}$ Mas a visualização estética não coincide meramente com a intuição dos fenômenos. É aqui que fica evidente a diferença entre o apolíneo na ciência e o apolíneo na arte, porque com a arte apolínea emerge a contraposição à "realidade cotidiana". ${ }^{57}$ No mundo das aparências jamais poderemos localizar tamanha proporção e simetria, pertencentes ao ideal, ao onirismo apolíneo. Assim, com essa entrada no ideal viabilizada pelo ritmo, o tempo se converte em espaço e, com isso, a vivência da eternidade é alcançada. $\mathrm{O}$ ritmo é uma arquitetura de

49 Griechische Rhythmik, KGW II, 3.IO4.

50 Rhythmische Untersuchungen, KGW II, 3.338.

5I A menor unidade do tempo, importante ressaltar, não equivale a uma unidade matemática. "Duas batidas [Takte] não serão jamais matematicamente idênticas [...] Assim como a forma de uma folha é idealmente sempre a mesma, não sendo, porém, a mesma na realidade [Wirklichkeit], o mesmo vale também para a igualdade dos ritmos, dos períodos, das estrofes. O balanço de um pêndulo nos desconcerta: dá-nos um esqueleto matemático" (Aufzeichnungen zur Metrik und Rhythmik, KGW II, 3.205). Contra Porter e Günther, Carlotta Santini elaborou um argumento bastante interessante a respeito do caráter não matemático do chronos prôtos nietzschiano. Cf. Santini, 20I6, pp. I29-I40.

52 Griechische Rhythmik, KGW II, 3.136.

53 Fragmento Póstumo 5 [90] de setembro de i870/janeiro de I871, KSA 7.II7.

54 A Visão dionisíaca de Mundo $\$$ I, KSA I.557.

55 Helmholtz, em Die Lehre den Tonenempfindungen als physiologische Grundlage für die Theorie der Musik, obra que Nietzsche consulta em I870, dirá que sem uma escala, um movimento, musical ou temporal, não poderia ser visto. Sobre a possível influência de Helmholtz nas reflexões de Nietzsche sobre o ritmo, cf. Günther, 2008, p. 29 e 30.

56 Aufzeichnungen zur Rhythmik und Metrik, KGW II, 3.225.

57 O Nascimento da Tragédia \$ I, KSA I.27. 
sons, e é na arquitetura que nos deparamos com a "eternidade".$^{58}$

\section{b) Harmonia}

A sensação de eternidade também é produzida pela música dionisíaca. Dionisíaco exprime a transição da música espacializada do ritmo apolíneo para a música temporalizada da harmonia. Porém, veremos que o tempo da harmonia, contínuo, difere do tempo fugaz, descontínuo, das aparências, sendo por meio dessa experiência temporal singular que a eternidade é atingida. Importante reparar que a eternidade agora é dotada de estatuto ontológico. Enquanto a música apolínea, o ritmo, é um fim, visto que ela é inteiramente capaz de despertar a sensação de eternidade, a música dionisíaca, a harmonia, é um meio que visa a simbolizar o ser eterno. Retomando a senda de Creuzer, Müller e Baschofen, Nietzsche confere uma aura de mistério a Dionisio, que exprime a passagem mística para um outro mundo. ${ }^{59}$ É, portanto, com o dionisíaco que a arte verdadeiramente reconquista a sua especificidade metafísica.

A música dionisíaca, quando comparada com a música apolínea, pode ser entendida como um tipo de música mais legítima, sendo ela que se coaduna com o caráter primordial e universal da linguagem, tal como abordado acima. Isso acontece em razão da harmonia ser um "símbolo da essência da vontade", enquanto o ritmo se mantém exterior à vontade. É essa música que "espelha a vontade", a "música verdadeiramente dionisíaca" ${ }^{11}$ Vimos que o ritmo, embora impulsione um afastamento do mundo das aparências, continua inserido num âmbito apenas intuitivo; a harmonia, por sua vez, estimula uma completa perda de intuitividade que torna possível a vivência metafísica. Essa propensão decorre da natureza sucessiva da harmonia. Essa é outra diferença relevante entre apolíneo e dionisíaco, porque ao passo que Apolo é "o deus eterno que igualiza todas as coisas na conflagração do mundo", Dionísio expressa a "metamorfose do mundo" ${ }^{62}$ Não obstante essa colocação, a sucessão provocada na harmonia não corresponde à sucessão do tempo das aparências. ${ }^{63}$ Pois se é certo que é "a sucessão que exprime a vontade", ao contrário da justaposição, que manifesta "o repouso na

58 Fragmento Póstumo 5 [73] de setembro de I870/janeiro de I87i, KSA 7.IO9.

59 Sobre as características muito singulares de Dionísio para o jovem Nietzsche, cf. Reibnitz, I992, p. 62 e 63. Para um estudo mais abrangente sobre o assunto, cf. Lima, 2006.

60 A Visão dionisíaca de Mundo $\$ 4$, KSA I.574.

6I O Nascimento da Tragédia \$ I7, KSA I.II2.

62 Fragmento Póstumo 8 [46] do inverno de I870-71/outono de I872, KSA 7.240.

63 Por essa razão, penso que Günther se precipita ao supor que Nietzsche almeja tão somente promover uma junção entre eternidade (apolíneo) e mudança (dionisíaco). Cf. Günther, 2008, p. 46. 
intuição", isso se dá após uma correção da concepção espacializada de sucessão. É um "embaraço dos princípios da arte", assevera Nietzsche, "aplicar à sucessão leis de justaposição", visto que as leis da sucessão devem ser buscadas em fenômenos qualitativos, como "nas cores que se desafiam mutuamente, nas dissonâncias que aspiram a uma liberação [Auflösung], na sequência das correntes de disposições [Gemüthsströmungen]". ${ }^{64}$ Existe, assim, um elemento de continuidade inerente à sucessão harmônica. Uma "fala cantada", como no coro, "não pode ser algo como uma sequência de sons de palavras", pois a palavra possui, nesse caso, "uma sonoridade e um tom relativos". ${ }^{65}$ Dionisiacamente compreendido, o som incita um efeito sintético; "ele une, enquanto o olho separa" ${ }^{66}$ Trata-se de um sentimento que excede a individualidade, delineando o sentimento mistico de unidade. $\mathrm{O}$ homem sente-se não só unido com o seu próximo, mas também ao ser, consolidando o desprendimento das aparências e do peso do vir-a-ser. É a "arte dionisíaca" que exprime "a vontade em sua onipotência, por trás do principium individuationis, a vida eterna para além de toda a aparência e apesar de todo o aniquilamento". ${ }^{67}$ Esse é o "consolo metafísico que nos arranca momentaneamente da engrenagem das figuras mutantes". ${ }^{68}$

Há um aspecto inquietante nessa proposta. Porque se a música dionisíaca cria as condiçõos para a imersão na eternidade, esse é um acontecimento momentâneo, de modo que o sofrimento, ao invés de ser abrandado, poderia ser intensificado, visto que não haveria realmente uma saída do mundo da aparência e, consequentemente, das incursôes do tempo enquanto Kronos. Entretanto, Nietzsche entende que os antigos encontraram uma maneira de evitar esse problema através do mito; o mito propicia o prolongamento da vivência dionisíaca da eternidade.

Até então os gregos haviam se sentido instintivamente compelidos a conectar tudo o que era vivenciado a seus mitos, sim, a compreendê-los somente através dessa vinculação: com o que também o presente mais próximo havia de se lhes apresentar desde logo sub specie aeterni, no sentido preciso de aparecer sem tempo. Nessa corrente do atemporal mergulharam, porém, tanto o Estado como a arte, para nele encontrar repouso do peso e da avidez do instante [Augenblick]. E um povo - como de resto também um homem - vale precisamente tanto quanto é capaz de imprimir em suas vivências o selo do eterno, pois

64 Fragmento Póstumo I [53] do outono de I869, KSA 7.26.

65 Fragmento Póstumo 3 [16] do inverno de I869-70/primavera de I870, KSA 7.64.

66 Fragmento Póstumo I6 [13] do verão de I871/primavera de I872, KSA 7.397.

67 O Nascimento da Tragédia $₫$ I6, KSA I.Io8.

68 O Nascimento da Tragédia $\$$ I7, KSA I.IO9. 
com isso fica como que desmundanizado e mostra a sua convicção íntima e inconsciente acerca da relatividade do tempo e do significado verdadeiro, i.e, metafísico, da vida. ${ }^{69}$

No início da recepção de Nietzsche na Alemanha, ele foi frequentemente rotulado como o iniciador de uma nova mitologia; basta lembrarmo-nos das conhecidas leituras feitas pelo George-Kreis e Ernst Bertram. Após as investigações críticas de Montinari, foi preciso empreender uma revisão dessa posição, o que nos fez ver como Nietzsche esteve, na maior parte do tempo, engajado com posturas filosóficas mais afeitas a um certo tipo de iluminismo. ${ }^{70}$ É manifesto, contudo, que Nietzsche, na época de $O$ Nascimento da Tragédia, elaborou uma filosofia do mito, imprescindível para a economia geral de seu pensamento no início de 1870 . E, nesse contexto, o mito cumpre um duplo papel: impedir a dissolução do indivíduo na experiência musical dionisíaca, que poderia sucumbir diante da revelação da dor e contradição enquanto essência do ser, e também fazer com que o elemento religioso contido nessa experiência pudesse ser resguardado ao longo da vida. Eu gostaria de fazer algumas breves considerações sobre esse último ponto antes de encerrar o texto.

Segundo Nietzsche, "o mito trágico só deve ser compreendido como uma visualização da sabedoria dionisíaca através de meios artísticos apolíneos" ${ }^{71}$ Ele possui não um apelo moral, mas estritamente estético. $\mathrm{O}$ mito é o correlato imagético, apolíneo, da revelação metafisica propiciada pela música dionisíaca. É um processo intrínseco à música dionisíaca manifestar-se em imagens, com incumbência simbólica. Assim, a experiência musical dionisíaca transforma as imagens, inoculando-as de valor religioso. Com a transformação religiosa, a imagem, agora tornada mito, exprime uma "verdade universal e eterna" ${ }^{172}$, dissolvendo os fatos históricos, que passam a ser vistos como "livres seres míticos" ${ }^{73}$ Esse quadro exibe a vantajosa ambiguidade do mito: porque se trata de um recurso apolíneo a serviço de um propósito metafísico, que excede o universo imagético, provocando a desmundanização. Somente com o mito, portanto, que a experiência metafísica dionisíaca perdura, fazendo com que a eternidade do ser seja pressentida a cada momento. Essa é uma proeza inalcançável para os conceitos, o que mostra que, para Nietzsche, os mitos manifestam a posse mais vigorosa de uma cultura, e não um estágio de imaturidade que precede

69 O Nascimento da Tragédia $\$ 23$, KSA I.I47 e I48.

70 Cf. Salaquarda, 1979, pp. I74-178.

7I O Nascimento da Tragédia $\$ 22$, KSA I.I4I.

72 Fragmento Póstumo I4 [3] da primavera de I871/início de I872, KSA 7.376.

73 Fragmento Póstumo 9 [58] de I871, KSA 7.296. 
o pensamento abstrato. Uma cultura dirigida por conceitos, sem mito, como é a cultura moderna, desmorona, uma vez que só pode ter em seu horizonte a perniciosa transitoriedade, a ausência de "sede originária, fixa e sagrada". ${ }^{74}$

\section{Referências}

Behler, E. Die Sprachteorie des frühen Nietzsche. In: Borsche, T., Gerratana, F., Venturelli, A. (Hrsg.) 'Centauren-Geburten'. Wissenschaft, Kunst und Philosophie beim jungen Nietzsche. Berlin/New York: Walter de Gruyter, 1994.

GüNTHER, F. F. Rhythmus beim frühen Nietzsche. Berlin/New York: Walter de Gruyter, 2008.

Lima, M. J. S. As máscaras de Dioniso. Filosofia e tragédia em Nietzsche. São Paulo: Discurso/Unijuí, 2006.

Mоsт, O. Zeitliches und Ewiges in der Philosophie Nietzsches und Schopenhauers. Frankfurt am Main: Vittorio Klostermann, 1977.

Nasser, E. Sul cristianesimo del giovane Nietzsche. In: Busellato, S. (Org.) Nietzsche dal Brasile. Trad. Giancarlo Micheli, Frederico Nacci, Stefano Busellato. Pisa: Edizioni ETs, 2014.

Nasser, E. Nietzsche e a ontologia do vir-a-ser. São Paulo: Edições Loyola, 2015.

NASSER, E. Transfigurações do passado: aspectos do problema do tempo na II Consideração extemporânea. In: Cadernos Nietzsche, v. 38, n. 2, 2017.

Nietzsche, F. Werke. Kritische Gesamtausgabe (KGw). Berlin/New York: Walter de Gruyter, 1967-1978.

Nietzsche, F. Werke. Kritische Studienausgabe (кsA). Berlin/New York: Walter de Gruyter, 1999.

Nietzsche, F. Sämtliche Briefe: Kritische Studienausgabe (кSAв). Berlin/ New York: Walter de Gruyter, 1986.

Porter, J. Nietzsche and the Philology of the Future. Stanford: Stanford University Press, 2000.

Reibnitz, B. Ein Kommentar zu Friedrich Nietzsche "Die Geburt der Tragödie aus dem Geiste der Musik"(Kapitel 1 - 12). Stuttgart: J. B. Metzler, 1992.

Salaquarda, J. Mythos bei Nietzsche. In: Poser, H. (Hrsg.) Philosophie und Myhos - Ein Kolloquium. Berlin/New York: Walter de Gruyter, 1979.

Santini, C. Nietzsche \& la rythmique grecque. Une approche philologique \& anthropologique. In: Les cahier philosophiques de Strasbourg, II, 2016.

74 O Nascimento da Tragédia $\$ 23$, KSA I.I46. 
Schмidt, J. Kommentar zu Nietzsches Die Geburt der Tragödie. Berlin/New York: Walter de Gruyter, 2012.

Schopenhauer, A. Die Welt als Wille und Vorstellung I. In: Sämtliche Werke Band I. Stuttgart: Suhrkamp, 1986.

Schopenhauer, A. Parerga und Paralipomena II. In: Sämtliche Werke Band V. Frankfurt am Main: Suhrkamp, 1986.

Stambaugh, J. Untersuchungen zum problem der Zeit bei Nietzsche. Den Haag: Martinus Nijhoff, I959.

Williamson, G. S., The Longing for Myth in Germany. Religion and Aesthetic Culture from Romanticism to Nietzsche. Chicago: The University of Chicago Press, 2017. 